\title{
Favourable effects of consuming a Palaeolithic- type diet on characteristics of the metabolic syndrome: a randomized controlled pilot-study
}

Inge Boers ${ }^{1,2^{*}}$, Frits AJ Muskiet ${ }^{3}$, Evert Berkelaar ${ }^{2}$, Erik Schut ${ }^{2}$, Ria Penders ${ }^{2}$, Karine Hoenderdos ${ }^{4}$, Harry J Wichers ${ }^{5}$ and Miek C Jong ${ }^{1,6,7}$

\begin{abstract}
Background: The main goal of this randomized controlled single-blinded pilot study was to study whether, independent of weight loss, a Palaeolithic-type diet alters characteristics of the metabolic syndrome. Next we searched for outcome variables that might become favourably influenced by a Paleolithic-type diet and may provide new insights in the pathophysiological mechanisms underlying the metabolic syndrome. In addition, more information on feasibility and designing an innovative dietary research program on the basis of a Palaeolithic-type diet was obtained.

Methods: Thirty-four subjects, with at least two characteristics of the metabolic syndrome, were randomized to a two weeks Palaeolithic-type diet $(n=18)$ or an isoenergetic healthy reference diet, based on the guidelines of the Dutch Health Council $(n=14)$. Thirty-two subjects completed the study. Measures were taken to keep bodyweight stable. As primary outcomes oral glucose tolerance and characteristics of the metabolic syndrome (abdominal circumference, blood pressure, glucose, lipids) were measured. Secondary outcomes were intestinal permeability, inflammation and salivary cortisol. Data were collected at baseline and after the intervention.

Results: Subjects were 53.5 (SD9.7) year old men $(n=9)$ and women $(n=25)$ with mean BMl of $31.8\left(\right.$ SD5.7) $\mathrm{kg} / \mathrm{m}^{2}$. The Palaeolithic-type diet resulted in lower systolic blood pressure $(-9.1 \mathrm{mmHg} ; P=0.015)$, diastolic blood pressure $(-5.2 \mathrm{mmHg} ; P=0.038)$, total cholesterol $(-0.52 \mathrm{mmol} / \mathrm{l} ; P=0.037)$, triglycerides $(-0.89 \mathrm{mmol} / ; ; P=0.001)$ and higher $\mathrm{HDL}$-cholesterol $(+0.15 \mathrm{mmol} / / ; P=0.013)$, compared to reference. The number of characteristics of the metabolic syndrome decreased with $1.07(P=0.010)$ upon the Palaeolithic-type diet, compared to reference. Despite efforts to keep bodyweight stable, it decreased in the Palaeolithic group compared to reference $(-1.32 \mathrm{~kg} ; P=0.012)$. However, favourable effects remained after post-hoc adjustments for this unintended weight loss. No changes were observed for intestinal permeability, inflammation and salivary cortisol.
\end{abstract}

Conclusions: We conclude that consuming a Palaeolithic-type diet for two weeks improved several cardiovascular risk factors compared to a healthy reference diet in subjects with the metabolic syndrome.

Trial registration: Nederlands Trial Register NTR3002

Keywords: Palaeolithic diet, Prevention, Metabolic syndrome, Weight loss correction

\footnotetext{
* Correspondence: i.boers@louisbolk.nl

'Department Nutrition and Health, Louis Bolk Institute, Hoofdstraat 24, Driebergen, LA 3972, the Netherlands

${ }^{2}$ Department of Clinical Psycho-Neuro-Immunology, University of Gerona, Gerona, Spain

Full list of author information is available at the end of the article
} 


\section{Background}

The metabolic syndrome (MetS) is a clustering of symptoms that usually derive from a combination of over nutrition and a sedentary lifestyle [1]. Because of the worldwide rapidly increasing prevalence of the MetS and its high risk of progression to type 2 diabetes mellitus (DM2) [2,3] and cardiovascular disease (CVD) [4], preventive measures are urgently needed. Lifestyleinduced insulin resistance and chronic systemic low grade inflammation may be central in the pathophysiological cascade towards the MetS [5]. Although dietary management and lifestyle modifications are the cornerstones in the treatment and prevention of metabolic disorders, specific guidelines for the MetS have not yet been established. There is considerable evidence that the dietary composition may favourably affect the components of the MetS. Various authors have pointed at the discordance between our contemporary diet and that of our Palaeolithic ancestors, which has shaped our core metabolism and physiology during the past 2.5 million years. Evolution predicts that such diets may also be optimal for prevention and treatment of metabolic disorders associated with obesity, DM2, CVD and insulin resistance [6-13]. Previously reported studies with Palaeolithic-type diets were conducted with healthy subjects [14,15] or patients with CVD [16], DM2 [17] or obesity $[18,19]$. There are no studies on the effects of a Palaeolithic-type diet targeting subjects with the MetS. The conducted trials showed that Palaeolithic-type diets may effectively lower bodyweight, waist circumference and BP [14], lower serum lipids [18] and improve insulin response in healthy volunteers within less than three weeks [15]. A major limitation of these three studies was the lack of a reference group. Controlled studies in patients with ischaemic heart disease [16], DM2 [17] or obese postmenopausal women [19], without correction for possible weight loss, showed a larger improvement of various CVD risk factors after consuming a Palaeolithic-type diet. Consequently, it is uncertain whether any of the positive health effects in these studies could also be on account of the accompanying weight loss as opposed to the composition of the Palaeolithic-type diet per se.

The main goal of the current pilot study was to compare metabolic effects of a Palaeolithic-type diet with those of a healthy reference diet, independent of weight loss, in subjects with the MetS. Next we studied outcome variables that might become favourably influenced by a Palaeolithic-type diet, and thereby provide new insights into the pathophysiological mechanisms underlying the MetS and CVD. The third goal was to obtain more information on feasibility and how to design and develop an innovative dietary research program on the basis of a Palaeolithic-type diet.

\section{Methods}

\section{Study design}

This was a stratified (men/women), randomized controlled single-blinded pilot study conducted in the Netherlands. Subjects with characteristics of the MetS were randomized to a two weeks dietary intervention with either a Palaeolithic-type diet or a healthy reference diet. Emphasis was put on the prevention of weight loss during the intervention. The study took place at the Louis Bolk Institute in Driebergen, the Netherlands, in October-December 2011. Laboratory measurements were performed in the Diakonessenhuis, Zeist, the Netherlands.

\section{Subjects}

Eligible subjects were 18-70 years old adults who gave written consent and had at least two of the following characteristics of the MetS [20]: 1. Central obesity (waist circumference $\geq 102 \mathrm{~cm}$ for men and $\geq 88 \mathrm{~cm}$ for women) 2. Elevated triglycerides $\geq 1.7 \mathrm{mmol} / \mathrm{l} 3$. Reduced HDLcholesterol $<1.0 \mathrm{mmol} / \mathrm{l}$ for men and $<1.3 \mathrm{mmol} / \mathrm{l}$ for women) 4. Raised BP $\geq 130 / 85 \mathrm{mmHg}$ or BP medication and 5. Elevated fasting plasma glucose $\geq 5.6 \mathrm{mmol} / \mathrm{l}$. Exclusion criteria were DM2, CVD, smoking, systolic BP > $180 \mathrm{mmHg}$, hypoglycaemic medication, pregnancy and severe internal or psychiatric disease. The study was approved by the Medical Ethics Committee Wageningen University and conducted according to the principles expressed in the Declaration of Helsinki.

\section{Study settings}

Subjects were recruited in September-October 2011 through advertisements in local newspapers and posters in primary health care units. After telephone contact a first selection was made and subjects were enrolled during a screening visit by the research physician. It was not known to the subjects whether any of the diets would be superior to the other (single-blinded). After randomization, subjects of the different diet groups could not communicate with each other. Before and directly after the intervention period subjects visited the Diakonessenhuis in Zeist for physical measurements, OGTT and blood sampling. All meals were delivered at their homes free of charge by a catering service.

\section{Dietary interventions}

The Palaeolithic-type diet intervention was based on anthropological Palaeolithic research [21,22] with a concern for feasibility in modern times. It was based on lean meat, fish, fruit, leafy and cruciferous vegetables, root vegetables, eggs and nuts. Dairy products, cereal grains, legumes, refined fats, extra salt and sugar were not part of it. The reference diet was based on the guidelines for a healthy diet of the Dutch Health Council [23-31]. Both diets were designed as seven consecutive daily menus 
(breakfast, lunch, dinner and snacks) and provided on the basis of an isoenergetic intake of $8700 \mathrm{~kJ}$. Although coffee and tea were not part of a Palaeolithic-type diet, subjects were allowed to drink, in view of possible withdrawal symptoms, up to two cups of coffee or black tea per day. Any medication was continued at the same dosages. Additional detailed information on the two diets is summarized in Table 1.

\section{Prevention of weight loss}

Before the intervention all subjects recorded their usual diet using a food record diary. This diary was used by the dietician to adjust diets to individual energy demand by providing (additional) program-related snacks to prevent weight loss within the intervention period. Bodyweight was measured every second day. A daily bodyweight fluctuation of $2 \mathrm{~kg}$ was considered acceptable. Next to keeping bodyweight stable, importance was emphasized of keeping their usual exercise level during the intervention.

\section{Compliance}

To ensure compliance to the intervention, all subjects were requested to keep records of the food consumed. In addition, each subject was encouraged every other day by telephonic contact with their personal coach to complete all meals and to discuss their progress, bodyweight fluctuation, possible physical and psychological discomforts or adverse events. A total of six personal coaches (each coaching 5-6 subjects) were involved during the study, who could be reached by the subjects for any questions concerning catering, daily recording or measurements.

\section{Outcomes}

Primary endpoints were glucose tolerance measured by the oral glucose tolerance test (OGTT) [32] and the characteristics of the MetS (waist circumference, systolic/diastolic BP, lipids, fasting glucose). Additional analyses comprised intestinal permeability, inflammation parameters (hsCRP, TNF $\alpha$ ) and a stress parameter (salivary cortisol). Tolerability was measured by analysing the adverse events reported during the study and by performing blood tests for haematological indices and liver and kidney functions.

\section{Measurements}

Systolic and diastolic BP, from which the mean values were calculated, were measured twice after at least 10 min of sitting using an automated BP measuring device (OMRON M6 Comfort, OMRON Healthcare Co. Ltd.). Bodyweight was measured using a digital Seca 803 scale. For the OGTT subjects ingested a solution containing a 75 g glucose load. Plasma glucose and insulin
Table 1 Nutrient and caloric composition of the dietary intervention programs

\begin{tabular}{|c|c|c|c|c|c|}
\hline \multirow[t]{2}{*}{ Nutrient } & \multicolumn{2}{|c|}{ Palaeolithic $^{\mathrm{a}}$} & \multicolumn{2}{|c|}{ Reference $^{a}$} & \\
\hline & & & En & $n \%$ & En\% \\
\hline Energy (kJ) & & 8703 & & 8690 & 8374 \\
\hline Protein $(\mathrm{en} \%),(\mathrm{g})$ & 24 & 123 & 17 & 91 & $10-25$ \\
\hline vegetable protein (g) & & 22 & & 39 & none \\
\hline animal protein (g) & & 101 & & 52 & none \\
\hline Carbohydrate (en\%),(g) & 32 & 164 & 50 & 261 & $40-70$ \\
\hline mono/disaccharides (g) & & 132 & & 109 & none \\
\hline Fat $(e n \%),(g)$ & 41 & 94 & 29 & 68 & $20-40$ \\
\hline saturated (en\%),(g) & 10 & 24 & 9 & 21 & $<10$ \\
\hline monounsaturated (g) & & 44 & & 26.5 & none \\
\hline polyunsaturated (g) & & 19 & & 14.6 & none \\
\hline linoleic acid (g) & & 14 & & 11 & $4-6$ \\
\hline EPA (mg) & & 640 & & 210 & $\begin{array}{r}E P A+D H A: \\
450\end{array}$ \\
\hline $\mathrm{DHA}(\mathrm{mg})$ & & 950 & & 360 & $\begin{array}{r}E P A+D H A: \\
450\end{array}$ \\
\hline Fibre $(e n \%),(g)$ & 3 & 34 & 2.7 & 28 & $30-40$ \\
\hline Sodium (mg) & & 2194 & & 2121 & $<2400$ \\
\hline Potassium (mg) & & 5859 & & 3932 & 4700 \\
\hline Calcium (mg) & & 575 & & 1181 & 1000 \\
\hline Magnesium (mg) & & 494 & & 415 & $250-300$ \\
\hline Iron (mg) & & 16.4 & & 12.6 & $8-15$ \\
\hline Selenium (mg) & & 110 & & 50 & $50-150$ \\
\hline Zinc (mg) & & 13.6 & & 12.0 & $9-10$ \\
\hline Phosphorus (mg) & & 1661 & & 1729 & $700-1400$ \\
\hline Copper (mg) & & 2.0 & & 1.4 & $1.5-3.5$ \\
\hline lodine (mcg) & & 138 & & 219 & 150 \\
\hline Vitamin A (mcg) & & 1317 & & 705 & $700-900$ \\
\hline Vitamin B1 (mg) & & 1.5 & & 1.0 & 1.1 \\
\hline Vitamin B2 (mg) & & 1.4 & & 1.7 & $1.1-1.5$ \\
\hline Vitamin B3 (mg) & & 35 & & 19 & $13-17$ \\
\hline Vitamin B6 (mg) & & 2.8 & & 1.7 & 1.5 \\
\hline Vitamin B12 (mcg) & & 11.5 & & 4.2 & 2.8 \\
\hline Vitamin C (mg) & & 264 & & 142 & 70 \\
\hline Vitamin D (mcg) & & 4.3 & & 3.7 & 3.3 \\
\hline Folate (mcg) & & 398 & & 331 & 300 \\
\hline
\end{tabular}

Abbreviation: En\%, energy percentage.

${ }^{\text {a }}$ Calculations were based on the Dutch NeVo table [30].

${ }^{\mathrm{b}}$ Recommended Dietary Allowances were based on recommendation of the Dutch Health Council [22-29].

concentrations were measured at 0 (baseline), 30, 60 and $120 \mathrm{~min}$ after ingestion. AUCs for glucose and insulin were calculated using the trapezoidal method. In addition $\mathrm{HOMA}_{\mathrm{IR}}$ and the ratio between triglycerides and HDL-cholesterol were determined as measures of 
insulin sensitivity. Urine was collected for assessment of intestinal permeability, which was measured using the differential sugar absorption test (DSAT). After an overnight fast, the subjects ingested a test solution containing $5 \mathrm{~g}$ lactulose, $2 \mathrm{~g}$ mannitol and $5 \mathrm{~g} \mathrm{D}$-xylose in $100 \mathrm{ml}$ water. All urine portions passed in the subsequent five hours were collected in a plastic container containing $0.5 \mathrm{ml} 20 \%$ chlorhexidine as a preservative. Results were expressed as the urinary lactulose:mannitol ratio. Saliva was collected by Salivette ${ }^{\curvearrowleft}$ devices for assessment of the diurnal cortisol slope. Subjects had to chew on the cotton swab for 30-60 seconds. Sampling was performed at wake time, 30-40 minutes after waking (peak time), $17.00 \mathrm{~h}$ and bedtime [33]. A flattening slope of the diurnal cortisol curve is related to lowgrade inflammation, insulin resistance and the MetS
[34-36]. At the end of the intervention, an evaluation form on feasibility and motivational aspects was filled out by all subjects.

\section{Statistical methods}

For this pilot design a sample size of 15 subjects per group was estimated to be sufficient, because in previous studies with Palaeolithic-type diets [15,21] the same number of subjects showed positive changes in BP, glucose tolerance, lipids and inflammation parameters within two weeks. To allow for an estimated 20\% drop out, the total number of subjects was set at 36 . Subjects were stratified into two groups according to gender and subsequently randomized using separate randomization lists as generated by the Random Allocation Software Program employing a random block size of 6 to

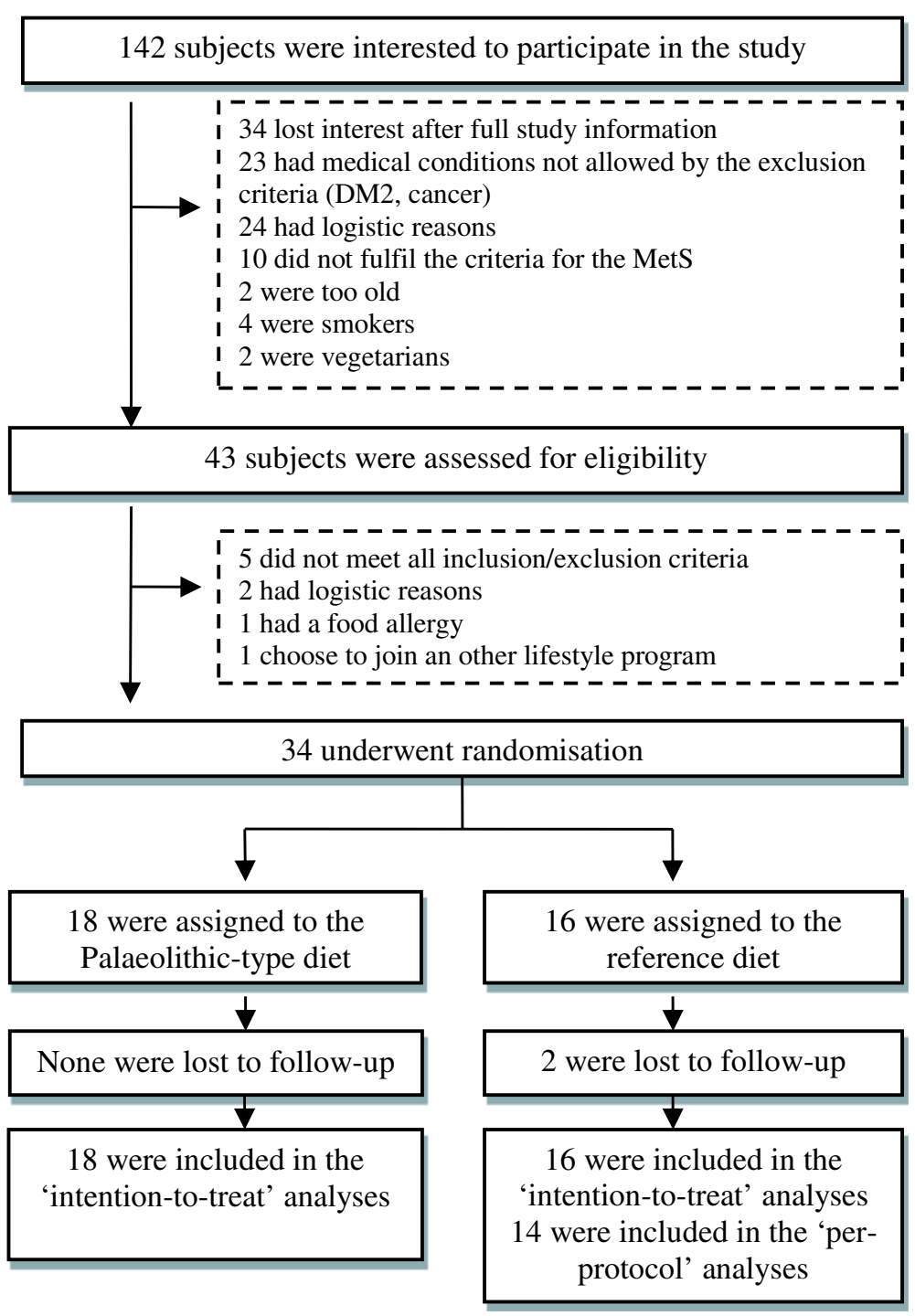

Figure 1 Flow diagram of the progress through enrolment, intervention allocation, follow-up, and data analysis. 
guarantee balanced allocation. The study monitor generated the random allocation sequence and assigned subjects to interventions. Descriptive statistics were calculated with regard to demographical and categorical data and mean scores and SDs of the numerical variables using SPSS (version 17.0). Evaluation occurred according to intention-to-treat. Mixed models were used to analyse between groups. This model included intervention, gender, intervention by gender, baseline BMI and the baseline value of the specific outcome variable as fixed effects, the intercept and subjects identification number as random effects. Pair wise comparisons between the two diets were made using the adjusted data. For these differences $95 \%$ confidence intervals were calculated. Two-way paired t-tests were used to analyse withinsubject changes per group according to per-protocol.

\section{Results}

The courses of inclusion and exclusion are shown in Figure 1. A total of 34 subjects were randomized: 18 were allocated to the Palaeolithic group and 16 to the reference group. Two subjects $(2 / 16 ; 12.5 \%)$ dropped out from the reference group for personal reasons. There were only a few at random missing cortisol data, attributable to some subjects who forgot to take a saliva sample.

\section{Baseline data}

Tables 2, 3 and 4 show the baseline demographic and clinical characteristics of all subjects. Baseline data differed between both groups for BMI and number of characteristics of the MetS. No differences were found for coffee, tea and alcohol consumption, or the amount of exercise and stress factors between the intervention groups. All outcome variables exhibited normal distributions.
Exception was the diurnal slope of cortisol showing a skewed distribution.

\section{Outcomes and estimation}

Study subjects were 9 men and 25 women with an average age of 53.5 (SD9.7) years, a mean BMI of 31.8 (SD5.7) and an average number of 3.2 (SD1.3) characteristics of the MetS. Compared to reference, the Palaeolithic group, had lower mean systolic BP $(-9.1 \mathrm{mmHg} ; P=0.015)$, diastolic BP $(-5.2 \mathrm{mmHg} ; P=0.038)$, total cholesterol $(-0.52 \mathrm{mmol} / \mathrm{l}$; $P=0.037)$ and triglycerides $(-0.89 \mathrm{mmol} / \mathrm{l} ; P=0.001)$ and a higher mean HDL-cholesterol $(+0.15 \mathrm{mmol} / \mathrm{l} ; P=0.013)$. For detailed results see Tables 3 and 4 . The number of characteristics of the MetS decreased upon the Palaeolithic-type diet $(-1.07$ characteristics; $P=0.010)$ compared to reference, resulting in less subjects with the actual MetS according to the definition of the MetS [20] after the intervention. There was a tendency for a larger decrease of AUC insulin in the Palaeolithic group (-1 $918 \mathrm{mU} / \mathrm{l} \mathrm{x}$ min versus $+362 \mathrm{mU} / \mathrm{l} \mathrm{x} \mathrm{min}$ in the reference group; $P=0.051)$ using two-tailed unpaired t-tests, however this difference did not remain when adjusted for baseline BMI. In both groups change was observed in waist circumference (Palaeolithic: $-3.1 \mathrm{~cm}$; reference: $-3.3 \mathrm{~cm}$ ), fasting glucose (Palaeolithic: $-0.9 \mathrm{mmol} / \mathrm{l}$; reference: $-0.35 \mathrm{mmol} / \mathrm{l}$ ) and the ratio between urinary sodium and potassium (Palaeolithic: -1.1 ; reference: -0.57 ), however no differences were seen between both groups. Fasting plasma insulin $(-2.7 \mathrm{mU} / \mathrm{l})$ and $\mathrm{HOMA}_{\mathrm{IR}}(-0.9)$ only decreased in the Palaeolithic group (Table 5 ). The ratio between total cholesterol and HDL-cholesterol $(-1.16 \mathrm{~mol} / \mathrm{mol}$; $P=0.003)$ and the ratio between triglycerides and HDLcholesterol $(-0.91 \mathrm{~mol} / \mathrm{mol} ; P=0.0001)$ were lowered in the Palaeolithic group compared to reference. Among

Table 2 Baseline demographic and clinical characteristics

\begin{tabular}{|c|c|c|c|c|c|}
\hline \multirow[t]{2}{*}{ Variable } & \multicolumn{2}{|c|}{ Palaeolithic (n 18) } & \multicolumn{2}{|c|}{ Reference ( $n$ 16) } & \multirow[t]{2}{*}{$P^{*}$} \\
\hline & Mean or $\%$ & SD & Mean or $\%$ & SD & \\
\hline \multicolumn{6}{|l|}{ Demographic } \\
\hline Gender: women (\%) & 72.2 & & 75.0 & & 0.86 \\
\hline Age (year) & 52.0 & 10.2 & 55.4 & 9.0 & 0.32 \\
\hline Race & & & & & 0.13 \\
\hline Caucasian (\%) & 100 & & 87.5 & & \\
\hline Asian (\%) & 0 & & 12.5 & & \\
\hline Characteristics of the MetS $(n)$, range $0-5$ & 3.7 & 1.1 & 2.7 & 1.3 & 0.02 \\
\hline (1) Abdominal circumference $\hat{\sigma} \geq 102 \mathrm{~cm}, q \geq 88 \mathrm{~cm}(\%)$ & 94.4 & & 100.0 & & 0.35 \\
\hline (2) Triglycerides $\geq 1.7 \mathrm{mmol} / /(\%)$ & 38.9 & & 18.8 & & 0.21 \\
\hline (3) HDL-cholesterol $\lesssim<1.0 \mathrm{mmol} / \mathrm{l}$, $q<1.3 \mathrm{mmol} / \mathrm{l}(\%)$ & 66.7 & & 12.5 & & 0.00 \\
\hline (4) $\mathrm{BP} \geq 130 / 85 \mathrm{mmHg}$ or $\mathrm{BP}$ medication (\%) & 83.3 & & 75.0 & & 0.56 \\
\hline (5) Glucose fasting $\geq 5.6 \mathrm{mmol} / \mathrm{l}(\%)$ & 77.8 & & 43.8 & & 0.04 \\
\hline
\end{tabular}

* $P$ values between the two intervention groups at baseline. 
Table 3 Summary results for each intervention group

Variable Palaeolithic ( $n$ 18)

Mean SD

\section{Anthropometric}

Bodyweight ( $\mathrm{kg}$ )

$\begin{array}{lll}\text { Baseline } & 98.0 & 18.2 \\ 2 \text { weeks } & 95.3 & 17.5\end{array}$

BMI $\left(\mathrm{kg} / \mathrm{m}^{2}\right)$

$\begin{array}{lll}\text { Baseline } & 33.7 & 5.9 \\ 2 \text { weeks } & 32.8 & 5.8\end{array}$

Abdominal circumference $(\mathrm{cm})$

$\begin{array}{lll}\text { Baseline } & 114.7 & 11.5 \\ 2 \text { weeks } & 111.6 & 12.3\end{array}$

Systolic BP (mmHg)

$\begin{array}{lll}\text { Baseline } & 131 & 15 \\ 2 \text { weeks } & 122 & 10\end{array}$

Diastolic BP (mmHg)

$\begin{array}{lll}\text { Baseline } & 87 & 9 \\ 2 \text { weeks } & 79 & 6\end{array}$

Characteristics of the MetS (n),

$\begin{array}{lll}\text { range } 0-5 & \text { Baseline } & 3.7 \\ 2 \text { weeks } & 2.7\end{array}$

\section{Glucose tolerance and insulin sensitivity}

Glucose fasting ( $\mathrm{mmol} / \mathrm{l})$

$\begin{array}{lll}\text { Baseline } & 6.1 & 0.8 \\ 2 \text { weeks } & 5.7 & 0.8\end{array}$

Insulin fasting (mU/)

$\begin{array}{ll}\text { Baseline } & 11.9 \\ 2 \text { weeks } & 9.2\end{array}$

HOMA ${ }_{\mathbb{R}}^{d}$

$\begin{array}{lll}\text { Baseline } & 3.3 & 1.7 \\ 2 \text { weeks } & 2.4 & 1.6\end{array}$

AUC glucose $(\mathrm{mmol} / \mathrm{l} \times \mathrm{min})$

$\begin{array}{lll}\text { Baseline } & 263 & 208 \\ 2 \text { weeks } & 245 & 199 \\ & & \\ \text { Baseline } & 8791 & 6200 \\ 2 \text { weeks } & 6873 & 2692\end{array}$

TG:HDL-C (mol/mol)

$\begin{array}{ll}\text { Baseline } & 1.7 \\ 2 \text { weeks } & 0.9\end{array}$

Lipids

TC (mmol/l)

$\begin{array}{lllll}\text { Baseline } & 5.7 & 1.0 & 6.1 & 1.4 \\ 2 \text { weeks } & 5.0 & 0.9 & 6.0 & 1.2\end{array}$

84.3

12.5

$29.7 \quad 5.2$

$107.7 \quad 9.4$

$104.7 \quad 8.7$

8.7

$134 \quad 15$

$129 \quad 14$

839

$\begin{array}{ll}2.7 & 1.3 \\ 2.9 & 1.2\end{array}$

1.3
1.2

$\begin{array}{ll}5.8 & 0.7 \\ 5.5 & 0.8\end{array}$

$10.2 \quad 6.5$

$9.5 \quad 5.3$

$2.7 \quad 1.8$

2.4

1.3

$\begin{array}{ll}249 & 162 \\ 262 & 216\end{array}$

$\begin{array}{ll}6270 & 3619 \\ 6955 & 3365\end{array}$

$\begin{array}{lll}0.7 & 1.1 & 0.7\end{array}$

0.7

0.6

$\frac{\text { Reference }(n \text { 16) }}{\text { Mean SD }}$

$P^{a}$

Difference $^{b}$

$$
-1.3(-2.3 ;-0.3)
$$

0.04

$-0.5(-0.9 ;-0.1)$

0.05

$-0.4(-2.4 ; 1.6)$

0.69

0.06

$-9.1(-16.2 ;-1.9)$

0.02

0.48

$$
-5.2(-10.0 ;-0.3)
$$

0.75

$$
-1.1(-1.9 ;-0.3)
$$

0.02

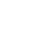

$$
-0.1(-0.5 ; 0.3)
$$

0.34

$-2 \cdot 0(-5.0 ; 1.1)$

0.40

$$
-0.5(-1.4 ; 0.4)
$$

$-27.7(-156.6 ; 101.1)$

0.66

0.83

$$
-1342 \cdot(-415 ; 3 \text { 099) }
$$

0.16

$$
-0.9(-1.3 ;-0.5)
$$

0.07 
Table 3 Summary results for each intervention group (Continued)

\begin{tabular}{|c|c|c|c|c|c|c|c|c|}
\hline \multirow[t]{3}{*}{$\mathrm{HDL}-\mathrm{C}(\mathrm{mmol} / \mathrm{l})$} & & & & & & & $0.2(0.0 ; 0.3)$ & 0.01 \\
\hline & Baseline & 1.3 & 0.4 & 1.6 & 0.4 & 0.06 & & \\
\hline & 2 weeks & 1.3 & 0.4 & 1.4 & 0.4 & & & \\
\hline \multirow[t]{3}{*}{ LDL-C (mmol/l) } & & & & & & & $-0.1(-0.5 ; 0.3)$ & 0.56 \\
\hline & Baseline & 3.5 & 0.7 & 3.9 & 1.4 & 0.27 & & \\
\hline & 2 weeks & 3.2 & 0.8 & 3.9 & 1.1 & & & \\
\hline \multirow[t]{3}{*}{$\mathrm{TG}(\mathrm{mmol} / \mathrm{l})$} & & & & & & & $-0.9(-1.3 ;-0.5)$ & 0.00 \\
\hline & Baseline & 1.9 & 1.4 & 1.3 & 0.6 & 0.10 & & \\
\hline & 2 weeks & 1.0 & 0.6 & 1.4 & 0.6 & & & \\
\hline \multirow[t]{3}{*}{ TC:HDL-C ( $\mathrm{mol} / \mathrm{mol})$} & & & & & & & $-1.2(-1.9 ;-0.4)$ & 0.00 \\
\hline & Baseline & 4.6 & 1.5 & 3.5 & 2.1 & 0.11 & & \\
\hline & 2 weeks & 4.0 & 1.3 & 4.5 & 1.5 & & & \\
\hline \multicolumn{9}{|l|}{ Inflammation } \\
\hline \multirow[t]{3}{*}{ hsCRP (mg/l) } & & & & & & & $0.1(-2.2 ; 2.3)$ & 0.96 \\
\hline & Baseline & 4.4 & 3.4 & 2.3 & 3.1 & 0.07 & & \\
\hline & 2 weeks & 4.6 & 3.1 & 3.0 & 4.5 & & & \\
\hline \multirow[t]{3}{*}{ TNFa (pg/ml) } & & & & & & & $-0.6(-1.7 ; 0.6)$ & 0.32 \\
\hline & Baseline & 3.9 & 1.8 & 4.3 & 3.0 & 0.65 & & \\
\hline & 2 weeks & 4.0 & 1.6 & 4.3 & 3.1 & & & \\
\hline \multicolumn{9}{|c|}{ Intestinal permeability } \\
\hline \multicolumn{4}{|c|}{ Lactulose:mannitol $(\mathrm{mol} / \mathrm{mol})$, in 5 h urine portion } & & & & $-0.007(-0.023 ; 0.008)$ & 0.35 \\
\hline & Baseline & 0.029 & 0.017 & 0.024 & 0.021 & 0.66 & & \\
\hline & 2 weeks & 0.024 & 0.013 & 0.033 & 0.025 & & & \\
\hline \multicolumn{9}{|l|}{ Stress parameter } \\
\hline \multicolumn{3}{|c|}{ Diurnal cortisol slope, wakeup-bedtime } & & & & & $-0.08(-0.36 ; 0.20)$ & 0.54 \\
\hline & Baseline & -0.41 & $-0.30 ;-0.72^{e}$ & -0.38 & $-0.30 ;-0.70^{\mathrm{e}}$ & 0.43 & & \\
\hline & 2 weeks & -0.40 & $-0.22 ;-0.54^{e}$ & -0.57 & $-0.28 ;-0.62^{\mathrm{e}}$ & & & \\
\hline
\end{tabular}

Abbreviations: TG triglycerides, HDL-C HDL-cholesterol, TC total cholesterol, LDL-C LDL-cholesterol.

Mean values and standard deviations, intention-to-treat.

${ }^{a} P$ values between the two intervention groups at baseline.

${ }^{\mathrm{b}}$ Difference $=$ Palaeolithic-type diet - reference diet. Values are $95 \% \mathrm{Cl}$.

${ }^{c} P$ values between the two intervention groups after the intervention.

${ }^{d}$ For $\mathrm{HOMA}_{\mathrm{IR}}$ the following equation was used: $\mathrm{HOMA}_{\mathrm{IR}}=$ (fasting insulin $\mathrm{mmol} / \mathrm{l} \times$ fasting glucose $\left.\mathrm{mU} / \mathrm{l}\right) / 22.4$.

'Data are median (25st; 75 st percentile).

tolerability outcomes the white blood cell count and $\gamma$-glutamyltransferase showed a decline in favour of the Palaeolithic group. Urine analysis showed lower values of magnesium and calcium in the Palaeolithic group compared to reference. Other secondary outcome parameters showed no changes.

In line with the protocol, we took efforts to keep bodyweight stable. For nine subjects extra diet-related snacks were necessary due to over $2 \mathrm{~kg}$ weight loss, without being hungry (seven in the Palaeolithic group $=38 \%$ versus two in the reference group $=14 \%$ ). Hunger was reported once by three subjects in the Palaeolithic group at the start of the intervention. According to food diaries and coach reports, all subjects were able to complete their dietary programs. At the end of the intervention bodyweight was nevertheless decreased in the Palaeolithic group compared to reference $(-1.32 \mathrm{~kg} ; P=0.012)$. After adding this (unintended) weight loss as a separate fixed effect in a post-hoc analysis we found that favourable effects remained for systolic BP, HDL-cholesterol, triglycerides, the ratio between triglycerides and HDLcholesterol, the ratio between total cholesterol and HDL-cholesterol and the number of characteristics of the MetS (Table 6).

\section{Adverse events}

One subject in the reference group reported a moderate adverse event (nausea and diarrhoea) during the intervention 
Table 4 Summary results for each intervention group - tolerability

\begin{tabular}{l} 
Variable \\
\hline Haematology \\
$\mathrm{Hb}(\mathrm{g} / \mathrm{l})$
\end{tabular}

\begin{tabular}{|c|c|c|c|}
\hline \multicolumn{2}{|c|}{ Palaeolithic (n 18) } & \multicolumn{2}{|c|}{ Reference ( $n$ 16) } \\
\hline Mean & SD & Mean & SD \\
\hline
\end{tabular}

$P^{\mathrm{a}} \quad$ Difference $^{\mathrm{b}} \quad P^{\mathrm{c}}$

$$
\mathrm{Hb}(\mathrm{g} / \mathrm{l})
$$

$\begin{array}{lllll}\text { Baseline } & 145.0 & 11.3 & 141.8 & 8.1 \\ 2 \text { weeks } & 145.0 & 11.3 & 143.4 & 9.7\end{array}$

$-1.6(-6.4 ; 3.2)$

Ht $(1 / l)$

$\begin{array}{lllll}\text { Baseline } & 0.43 & 0.03 & 0.42 & 0.03 \\ 2 \text { weeks } & 0.44 & 0.03 & 0.42 & 0.03\end{array}$

$\mathrm{RBC}\left(\times 10 \mathrm{E}^{12} /\right)$

$\begin{array}{lll}\text { Baseline } & 4.8 & 0.3 \\ 2 \text { weeks } & 4.8 & 0.3\end{array}$

$\mathrm{WBC}\left(\mathrm{x} 10 \mathrm{E}^{9} / \mathrm{I}\right)$

$0.3 \quad 4.7$

0.3

0.4

$-1.0(-1.7 ;-0.2)$

Platelets $\left(\mathrm{x} 10 \mathrm{E}^{9} / \mathrm{l}\right)$

$\begin{array}{ll}\text { Baseline } & 253.6 \\ 2 \text { weeks } & 240.2\end{array}$

44.4
51.5

Liver and kidney function

ASAT (U/I)

$\begin{array}{lll}\text { Baseline } \quad 27.6 & 7.0\end{array}$

26.3

25.3

6.8

6.6

$\operatorname{ALAT}(\mathrm{U} / \mathrm{l})$

$\begin{array}{lll}\text { Baseline } & 35.1 & 16.8 \\ 2 \text { weeks } & 38.2 & 17.7\end{array}$

GGT (U/I)

$\begin{array}{ll}\text { Baseline } & 27.3 \\ 2 \text { weeks } & 21.9\end{array}$

AP $(U / I)$

Baseline $\quad 79.3$

2 weeks $\quad 74.1$

Creatinine $(\mu \mathrm{mol} / \mathrm{l})$

$\begin{array}{ll}\text { Baseline } & 71.2 \\ 2 \text { weeks } & 75.6\end{array}$

Urea (mmol/l)

$\begin{array}{lllll}\text { Baseline } & 4.9 & 1.3 & 5.1 & 1.2 \\ \text { 2 weeks } & 5.7 & 1.6 & 6.0 & 1.3\end{array}$

\section{Other laboratory parameters}

Urine

Sodium (mmol/h)

$1.2 \quad 0.58$

Potassium (mmol/h)

$\begin{array}{lllll}\text { Baseline } & 3.5 & 1.3 & 4.0 & 1.6 \\ 2 \text { weeks } & 3.8 & 1.5 & 3.4 & 1.3\end{array}$


Table 4 Summary results for each intervention group - tolerability (Continued)

\begin{tabular}{|c|c|c|c|c|c|c|c|c|}
\hline \multirow[t]{3}{*}{ Magnesium (mmol/h) } & & & & & & & $-0.04(-0.07 ;-0.01)$ & 0.03 \\
\hline & Baseline & 0.14 & 0.06 & 0.14 & 0.06 & & & \\
\hline & 2 weeks & 0.13 & 0.08 & 0.13 & 0.06 & & & \\
\hline \multirow[t]{3}{*}{ Calcium (mmol/h) } & & & & & & & $-0.08(-0.12 ;-0.04)$ & 0.00 \\
\hline & Baseline & 0.13 & 0.13 & 0.19 & 0.20 & & & \\
\hline & 2 weeks & 0.08 & 0.05 & 0.16 & 0.10 & & & \\
\hline \multicolumn{3}{|c|}{ Sodium:potassium (mmol/mol) } & & & & & $-0.20(-0.62 ; 0.22)$ & 0.34 \\
\hline & Baseline & 2.12 & 1.16 & 1.78 & 0.67 & 0.31 & & \\
\hline & 2 weeks & 1.00 & 0.47 & 1.15 & 0.55 & & & \\
\hline \multicolumn{9}{|l|}{ Serum } \\
\hline \multirow[t]{3}{*}{ Homocysteine $(\mu \mathrm{mol} / \mathrm{l})$} & & & & & & & $1.05(-0.44 ; 2.55)$ & 0.16 \\
\hline & Baseline & 11.7 & 3.9 & 12.6 & 3.0 & 0.31 & & \\
\hline & 2 weeks & 12.9 & 4.3 & 12.8 & 3.1 & & & \\
\hline
\end{tabular}

Abbreviations: Ht Haematocrit, RBC Red blood cell count, WBC White blood cell count, ASAT Aspartate aminotransferase, ALAT Alanine amino transferase,

GGT $\mathrm{Y}$-Glutamyltransferase, AP Alkaline phosphatase.

Mean values and standard deviations, intention-to-treat

${ }^{\mathrm{a}} P$ values between the two intervention groups at baseline.

${ }^{\mathrm{b}}$ Difference $=$ Palaeolithic-type diet - reference diet (with $95 \% \mathrm{Cl}$ ).

${ }^{c} P$ values between the two intervention groups after the intervention.

which was not likely related to the intervention. Blood analysis concerning haematology and liver and kidney function showed no changes in relation to adverse events (Table 4).

\section{Discussion}

This is the first controlled study on the influence of a Palaeolithic-type diet in subjects with characteristics of the MetS. Over a two week period we found favourable changes in most characteristics of the MetS: a lowering of $\mathrm{BP}$, a change in lipid spectrum and a tendency to higher insulin sensitivity. Despite efforts to keep bodyweight stable, more weight loss was observed in the Palaeolithic group, which is an important outcome of our study. Nevertheless, favourable effects remained after adding weight loss as a separate fixed effect in a post-hoc analysis. No changes were found in specific inflammation parameters, intestinal permeability and the diurnal cortisol slope, possibly explained by the short duration of the dietary intervention or its constant bodyweight design. Indicators for new insights in the pathophysiological mechanisms underlying the MetS and CVD could possibly be found in the lowering effect on white blood cell count and lower levels of urinary calcium and magnesium. The generalizability of this study might be high, because of the broad inclusion criteria, men and women with diverse combinations and characteristics of the MetS.

\section{Interpretation}

Our results are in line with results from earlier research in related target groups. We found a lowering of systolic and diastolic BP, where in uncontrolled studies with healthy volunteers $[14,15]$ as well as in controlled studies with diabetic patients [17] lowering of BP has also been reported. Contrarily, BP lowering was not observed in controlled studies concerning patients with ischaemic disease [16] and obese postmenopausal women [19]. With respect to lipids, we found positive changes in total cholesterol, triglycerides and HDL-cholesterol in favour of the Palaeolithic group. Previous research also reported positive changes in lipid profile in healthy subjects, diabetic patients or obese women [15,17-19]. In our study, the ratio between total cholesterol and HDL-cholesterol, which is an important risk factor for CVD employed in clinical practice, was also lowered in the Palaeolithic group compared to reference. In addition, the ratio between triglycerides and HDL-cholesterol, a proxy for insulin resistance, was lowered in the Palaeolithic group compared to reference. Regarding glucose tolerance we did not find significant changes in our study. There was, however, a tendency for a larger decrease of AUC insulin and $\mathrm{HOMA}_{\mathrm{IR}}$ in the Palaeolithic group. In contrast to our results, glucose tolerance improved within 10-17 days in healthy subjects after a Palaeolithic diet in an uncontrolled study [15], as well as in a controlled study of longer duration (3 months) in patients with ischemic heart disease [16]. In our study we found for both groups a decrease in abdominal circumference of approx. $3 \mathrm{~cm}$, but not as a specific effect of the Palaeolithic-type diet. Earlier findings in 3 months [16,17] and 6 months [19] controlled studies did report change in abdominal circumference in favour of the Palaeolithic-type diet, 
Table 5 Differences between baseline and after intervention for both groups

\begin{tabular}{|c|c|c|c|c|c|c|c|c|c|}
\hline \multirow[t]{3}{*}{ Variable } & \multicolumn{9}{|c|}{ Paired Differences } \\
\hline & \multicolumn{3}{|c|}{ All (n 34) } & \multicolumn{3}{|c|}{ Palaeolithic ( $n$ 18) } & \multicolumn{3}{|c|}{ Reference $(n$ 14) } \\
\hline & Mean & SD & $P^{*}$ & Mean & SD & $P^{*}$ & Mean & SD & $P^{*}$ \\
\hline \multicolumn{10}{|l|}{ Anthropometric } \\
\hline Abdominal circumference $(\mathrm{cm})$ & -3.2 & 2.2 & 0.00 & -3.1 & 2.0 & 0.00 & -3.3 & 2.4 & 0.00 \\
\hline Systolic BP (mmHg) & -6.6 & 9.8 & 0.00 & -8.5 & 12.0 & 0.01 & -4.2 & 5.6 & 0.02 \\
\hline Diastolic BP (mmHg) & -6.0 & 7.5 & 0.00 & -8.0 & 8.3 & 0.0 & -3.5 & 5.6 & 0.03 \\
\hline \multicolumn{10}{|c|}{ Glucose tolerance and insulin sensitivity } \\
\hline Glucose fasting $(\mathrm{mmol} / \mathrm{l})$ & -0.4 & 0.5 & 0.00 & -0.4 & 0.5 & 0.01 & -0.4 & 0.4 & 0.00 \\
\hline Insulin fasting (mU/l) & -2.1 & 4.3 & 0.01 & -2.7 & 5.0 & 0.03 & -1.4 & 3.2 & 0.14 \\
\hline $\mathrm{HOMA} A_{\mathbb{R}}$ & -0.7 & 1.3 & 0.00 & -0.9 & 1.5 & 0.03 & -0.5 & 0.9 & 0.06 \\
\hline AUC glucose $(\mathrm{mmol} / \mathrm{l} \times \mathrm{min})$ & -6 & 141 & 0.81 & -18 & 170 & 0.66 & 9 & 98 & 0.73 \\
\hline AUC insulin (mU/I $x$ min) & -921 & 3565 & 0.15 & -1918 & 4361 & 0.08 & 362 & 1515 & 0.39 \\
\hline TG:HDL-C (mol/mol) & -0.4 & 1.0 & 0.04 & -0.8 & 1.2 & 0.01 & 0.2 & 0.3 & 0.08 \\
\hline \multicolumn{10}{|l|}{ Lipids } \\
\hline $\mathrm{TC}(\mathrm{mmol} / \mathrm{l})$ & -0.6 & 0.7 & 0.000 & -07 & 0.7 & 0.00 & -0.4 & 0.5 & 0.02 \\
\hline $\mathrm{HDL}-\mathrm{C}(\mathrm{mmol} / \mathrm{l})$ & -0.1 & 0.2 & 0.001 & -0.0 & 0.1 & 0.38 & -0.2 & 0.1 & 0.00 \\
\hline LDL-C (mmol/l) & -0.2 & 0.5 & 0.01 & -0.3 & 0.5 & 0.02 & -0.2 & 0.5 & 0.18 \\
\hline $\mathrm{TG}(\mathrm{mmol} / \mathrm{l})$ & -0.5 & 1.0 & 0.01 & -0.9 & 1.1 & 0.00 & 0.1 & 0.4 & 0.63 \\
\hline TC:HDL-C (mol/mol) & 0.1 & 1.2 & 0.72 & -0.5 & 0.7 & 0.01 & 0.9 & 1.3 & 0.03 \\
\hline \multicolumn{10}{|l|}{ Inflammation } \\
\hline hsCRP (mg/l) & 0.3 & 2.5 & 0.54 & 0.2 & 2.8 & 0.79 & 0.4 & 2.1 & 0.49 \\
\hline TNFa (pg/ml) & 0.2 & 1.3 & 0.45 & 0.1 & 1.6 & 0.87 & 0.3 & 0.7 & 0.13 \\
\hline \multicolumn{10}{|l|}{ Intestinal permeability } \\
\hline Lactulose:mannitol (mmol/mol) & 0.003 & 0.020 & 0.3 & -0.002 & 0.020 & 0.65 & 0.009 & 0.012 & 0.11 \\
\hline \multicolumn{10}{|l|}{ Other laboratory parameters } \\
\hline \multicolumn{10}{|l|}{ Urine } \\
\hline Sodium:potassium (mmol/mol) & -0.88 & 0.93 & 0.00 & -1.11 & 0.97 & 0.00 & -0.57 & 0.82 & 0.02 \\
\hline \multicolumn{10}{|l|}{ Serum } \\
\hline Homocysteine $(\mu \mathrm{mol} / \mathrm{l})$ & 0.8 & 1.6 & 0.01 & 1.2 & 1.3 & 0.00 & 0.3 & 1.9 & 0.60 \\
\hline
\end{tabular}

Abbreviations: TG triglycerides, HDL-C HDL-cholesterol, TC total cholesterol, LDL-C LDL-cholesterol.

Mean values and standard deviations, per-protocol.

${ }^{*} P$ values for the difference between baseline and after intervention, computed by two-tailed paired t-test, not adjusted.

in patients with ischemic disease and DM2 [16,17] or obese postmenopausal women [19]. Also other lowcarbohydrate, high-protein or Mediterranean diets have demonstrated to be effective in improving various markers of cardiovascular risk in diabetic patients [37]. Unique for our study was the attempt to find these favourable effects independently from the factor of weight loss. Another notable observation was that characteristics of the MetS can be reduced within a short period in people with cardiovascular risk.

A frequently expressed critique on Palaeolithic-type diets is related to their low calcium content. In our study there was indeed a $50 \%$ lower calcium intake compared to the reference diet (Table 1). However, due to higher dietary magnesium intake compared to reference and compensation by lower urinary calcium and magnesium excretion, calcium homeostasis was unlikely to have become compromised.

\section{Course of study and feasibility}

Home catering with frequent coaching was a satisfactory method to monitor the intake and whereabouts of the subjects. Subjects remained motivated and were coached to consume the prescribed food. Problems could be solved adequately resulting in few drop-outs and missing data. Nevertheless, we experienced that delivering fresh foods in time across a wide region of the Netherlands was a logistical challenge. For follow-up studies, attention to catering aspects is of utmost importance. The experienced difficulties in maintaining bodyweight could be part of the positive effects of a Palaeolithic-type diet. Jönsson et al. [38,39] 
Table 6 Post-hoc analysis: differences without and with weight loss added to the model

\begin{tabular}{|c|c|c|c|c|}
\hline Variable & Difference $^{a}$ & $P^{\mathrm{b}}$ & $\begin{array}{l}\text { Adjusted difference }{ }^{c} \\
\text { weight loss added to the model }\end{array}$ & $P^{\mathrm{b}}$ \\
\hline \multicolumn{5}{|l|}{ Anthropometric } \\
\hline Abdominal circumference $(\mathrm{cm})$ & $-0.4(-2.4 ; 1.6)$ & 0.69 & $-0.9(-3.2 ; 1.5)$ & 0.56 \\
\hline Systolic BP (mmHg) & $-9.1(-16.2 ;-1.9)$ & 0.02 & $-13.0(-25.4 ;-0.6)$ & 0.04 \\
\hline Diastolic BP (mmHg) & $-5.2(-10.0 ;-0.3)$ & 0.04 & $-4.9(-10.7 ; 0.9)$ & 0.09 \\
\hline Characteristics of the MetS $(n)$ & $-1.1(-1.9 ;-0.3)$ & 0.01 & $-1.0(-1.8 ;-0.1)$ & 0.03 \\
\hline \multicolumn{5}{|c|}{ Glucose tolerance and insulin sensitivity } \\
\hline Glucose fasting (mmol/l) & $-0.1(-0.5 ; 0.3)$ & 0.68 & $-0.0(-0.5 ; 0.5)$ & 0.91 \\
\hline Insulin fasting (mU/l) & $-2.0(-5.0 ; 1.1)$ & 0.20 & $-1.4(-5.1 ; 2.3)$ & 0.44 \\
\hline $\mathrm{HOMA}_{\mathbb{R}}$ & $-0.5(-1.4 ; 0.4)$ & 0.28 & $-0.5(-1.6 ; 0.7)$ & 0.41 \\
\hline AUC glucose $(\mathrm{mmol} / \mathrm{l} \times \mathrm{min})$ & $-28(-157 ; 101)$ & 0.66 & $-107(-247 ; 33)$ & 0.13 \\
\hline AUC insulin (mU/I x min) & $-1342(-415 ; 3$ 099) & 0.13 & $-484(-2503 ; 1535)$ & 0.63 \\
\hline TG:HDL-C (mol/mol) & $-0.9(-1.3 ;-0.5)$ & 0.00 & $-0.7(-1.1 ;-0.3)$ & 0.00 \\
\hline \multicolumn{5}{|l|}{ Lipids } \\
\hline $\mathrm{TC}(\mathrm{mmol} / \mathrm{l})$ & $-0.5(-1.0 ;-0.0)$ & 0.04 & $-0.3(-0.8 ; 0.3)$ & 0.35 \\
\hline $\mathrm{HDL}-\mathrm{C}(\mathrm{mmol} / \mathrm{l})$ & $0.2(0.0 ; 0.3)$ & 0.01 & $0.15(0.01 ; 0.29)$ & 0.04 \\
\hline LDL-C (mmol/l) & $-0.1(-0.5 ; 0.3)$ & 0.56 & $-0.1(-0.5 ; 0.4)$ & 0.75 \\
\hline $\mathrm{TG}(\mathrm{mmol} / \mathrm{l})$ & $-0.9(-1.3 ;-0.5)$ & 0.00 & $-0.7(-1.0 ;-0.3)$ & 0.00 \\
\hline TC:HDL-C (mol/mol) & $-1.2(-1.9 ;-0.4)$ & 0.00 & $-1.1(-2.0 ;-0.3)$ & 0.01 \\
\hline \multicolumn{5}{|l|}{ Inflammation } \\
\hline hsCRP (mg/l) & $0.1(-2.2 ; 2.3)$ & 0.96 & $0.1(-2.7 ; 2.8)$ & 0.95 \\
\hline TNFa (pg/ml) & $-0.6(-1.7 ; 0.6)$ & 0.32 & $-0.7(-2.0 ; 0.7)$ & 0.31 \\
\hline \multicolumn{5}{|l|}{ Intestinal permeability } \\
\hline Lactulose:mannitol (mmol/mol) & $-0.07(-0.023 ; 0.008)$ & 0.35 & $-0.012(-0.031 ; 0.008)$ & 0.24 \\
\hline \multicolumn{5}{|l|}{ Stress parameter } \\
\hline Diurnal cortisol slope & $-0.08(-0.36 ; 0.20)$ & 0.54 & $-0.10(-0.44 ; 0.25)$ & 0.24 \\
\hline wakeup-bedtime & & & & \\
\hline
\end{tabular}

Abbreviations: TG triglycerides, HDL-C HDL-cholesterol, TC total cholesterol, LDL-C LDL-cholesterol.

Adjusted differences after the intervention between both diets without and with weight loss added to the model.

${ }^{\text {a }}$ Difference $=$ Palaeolithic-type diet - reference diet (with $95 \% \mathrm{Cl}$ ).

${ }^{\mathrm{b}} P$ values between the two intervention groups after the intervention.

${ }^{\mathrm{c}}$ Adjusted difference = Palaeolithic-type diet - reference diet (with $95 \% \mathrm{Cl}$ ), percentage weight loss added to the model as fixed effect.

reported that a Palaeolithic diet is more satiating per calorie than a Mediterranean-like diet. The composition of a diet is likely to be an important factor in satiety and bodyweight management. It has been reported that a high protein content of a diet can increase satiety and weight loss $[40,41]$. What aspects of a Palaeolithic-type diet are important in this sense is yet unclear. Spreadbury et al. [42] reported that consuming a diet of grain-free whole foods may stimulate gastrointestinal microbiota more consistent with our evolutionary background. All of these factors might explain the apparent favourable effects of the modern "Palaeolithic" diets on satiety and metabolic health.

\section{Limitations}

It can be argued that a two weeks dietary intervention is too short to realize stable effects. Short term positive effects are followed by relapse in many dietary interventions. In our study comparison was made with a single blinded reference diet, rendering our results specific for the Palaeolithictype diet per se. Importantly, after two weeks $89 \%$ of the Palaeolithic group and 64\% of the reference group were still motivated to continue their dietary regimes. It will consequently be of utmost importance to study the longer term effects, as Mellberg et al. [19] have reported a significant decrease in body weight, fat mass and waist circumference after 6 months, not sustained after 24 months of a Palaeolithic-type diet compared to a reference diet in obese postmenopausal women. Specific aspects of the MetS, as glucose tolerance and probably also other characteristics, might become phenotypically apparent in the longer run, while even greater effects might be seen by allowing ad libitum consumption. 


\section{Conclusions}

We conclude that two weeks of a Palaeolithic-type diet, consumed by subjects with characteristics of the MetS, improved several cardiovascular risk factors compared to a healthy reference diet. It proved to be considerably difficult to keep bodyweight stable. Future studies might take full additional advantage of the greater weight loss in the Palaeolithic group by applying an ad libitum study design.

\begin{abstract}
Abbreviations
BP: Blood pressure; CVD: Cardiovascular disease; DM2: Type 2 diabetes mellitus; DSAT: Differential sugar absorption test; HOMA $\mathbb{I R}_{\mathrm{R}}$. Homeostasis model assessment of insulin resistance; hsCRP: High sensitivity C-reactive protein; MetS: Metabolic syndrome; OGTT: Oral glucose tolerance test.
\end{abstract}

\section{Competing interests}

The authors declare that they have no competing interests.

\section{Authors' contributions}

IB, MCJ, FAJM and HJW were responsible for acquisition, analysis and interpretation of the data and writing and revision of the manuscript. IB, MCJ, FAJM, HJW, ES, EB, RP and KH were responsible for designing the study, writing the study protocol, obtaining approval from the Medical Ethics Committee, acquisition of the data, coaching of participants and writing the manuscript. $\mathrm{KH}$ and FAJM were responsible for designing both intervention diets. IB and $\mathrm{KH}$ were responsible for the information meetings. IB and $\mathrm{MCJ}$ were responsible for recruitment. MCJ was study monitor and IB research physician. All authors read and approved the final manuscript.

\section{Acknowledgements}

We like to thank the technicians of the laboratories of the Diakonessenhuis in Zeist and the University Medical Centre in Groningen for their work and commitment. We are grateful to Eric van Veluwe, chef-de-cuisine and caterer to show all of his best efforts to manage catering aspects and professor Leo Pruimboom and dr. Henk Huizing for their expert advise. This study was supported by funding from the Innovatienetwerk, Stichting Junio, the University Medical Centre Groningen and the University of Gerona.

\section{Author details}

'Department Nutrition and Health, Louis Bolk Institute, Hoofdstraat 24, Driebergen, LA 3972, the Netherlands. ${ }^{2}$ Department of Clinical Psycho-Neuro-Immunology, University of Gerona, Gerona, Spain. ${ }^{3}$ Department of Laboratory Medicine, University Medical Centre Groningen, Groningen, the Netherlands. ${ }^{4}$ Scriptum Communication about Nutrition, IJsselstein, the Netherlands. ${ }^{5}$ Food and Biobased Research, Wageningen University \& Research centre, Wageningen, the Netherlands. ${ }^{6}$ Department of Health Sciences, Mid Sweden University, Sundsvall, Sweden. ${ }^{7}$ National Information and Knowledge Centre on Integrative Medicine (NIKIM), Amsterdam, the Netherlands.

Received: 9 July 2014 Accepted: 29 September 2014

Published: 11 October 2014

\section{References}

1. Cornier MA, Dabelea D, Hernandez TL, Lindstrom RC, Steig AJ, Stob NR, van Pet RE, Wang H, Eckel RH: The metabolic syndrome. Endocr Rev 2008, 29(7):777-822.

2. Grundy SM: Metabolic syndrome: connecting and reconciling cardiovascular and diabetes worlds. J Am Coll Cardiol 2006, 47(6):1093-1100.

3. Ford ES, Li C, Sattar N: Metabolic syndrome and incident diabetes: current state of evidence. Diabetes Care 2008, 31:1898-1904.

4. Gami AS, Witt BJ, Howard DE, Erwin PJ, Gami LA, Somers VK, Montori VM: Metabolic syndrome and risk of incident cardiovascular events and death: a systematic review and meta-analyses of longitudinal studies. J Am Coll Cardiol 2007, 49:403-414.

5. Ruiz-Núñez B, Pruimboom L, Dijck-Brouwer DA, Muskiet FA: Lifestyle and nutritional imbalances associated with Western diseases: causes and consequences of chronic systemic low-grade inflammation in an evolutionary context. J Nutr Biochem 2013, 24(7):1183-1201.

6. Cordain L, Eaton S, Sebastian A: Origins and evolution of the western diet Health implications for the 21st century. Am J Clin Nutr 2005, 81:341-354.

7. Eaton SB, Cordain L: Evolutionary aspects of diet: old genes, new fuels. Nutritional changes since agriculture. World Rev Nutr Diet 1997, 81:26-37.

8. Eaton SB, Eaton SB III: Paleolithic vs modern diets-selected pathophysiological implications. Eur J Nutr 2000, 39:67-70.

9. Jansson B: Dietary, total body and intracellular potassium-to-sodium ratios and their influence on cancer. Cancer Detect Prev 1990, 14:563-565.

10. Mann JI, De Leeuw I, Hermansen K, Karamanos B, Karlström B, Katsilambros N, Riccardi G, Rivellese AA, Rizkalla S, Slama G, Toeller M, Uusitupa M, Vessby B, Diabetes and Nutrition Study Group (DNSG) of the European Association: Evidence-based nutritional approaches to the treatment and prevention of diabetes mellitus. Nutr Metab Cardiovasc Dis 2004, 14(6):373-394.

11. O'Keefe $\mathrm{JH} \mathrm{Jr}$, Cordain L: Cardiovascular disease resulting from a diet and lifestyle at odds with our Paleolithic genome: how to become a 21st-century hunter-gatherer. Mayo Clin Proc 2004, 79:101-108.

12. Sebastian A, Frassetto LA, Sellmeyer DE, Merriam RL, Morris RC Jr: Estimation of the net acid load of the diet of ancestral preagricultural Homo sapiens and their hominid ancestors. Am J Clin Nutr 2002, 76:1308-1316.

13. Sebastian A, Frassetto LA, Sellmeyer DE, Morris RC Jr: The evolution-informed optimal dietary potassium intake of human beings greatly exceeds current and recommended intakes. Semin Nephrol 2006, 26(6):447-453.

14. Osterdahl M, Kocturk T, Koochek A, Wändell PE: Effects of a short-term intervention with a paleolithic diet in healthy volunteers. Eur J Clin Nutr 2008, 62(5):682-685

15. Frasetto LA, Schloetter M, Mietus-Synder M, Morris RC Jr, Sebastian A: Metabolic and physiologic improvement from consuming a paleolithic, hunter-gatherer type diet. Eur J Clin Nutr 2009, 63(8):947-955.

16. Lindeberg S, Jonsson T, Granfeldt Y, Borgstrand E, Soffman J, Sjostrom K, Ahren B: A Paleolithic diet improves glucose tolerance more than a Mediterranean-like diet in individuals with ischaemic heart disease. Diabetologia 2007, 50:1795-1807.

17. Jönsson T, Granfeldt Y, Ahrén B, Branell U, Palsson G, Hansson A Soderstrom M, Lindeberg S: Beneficial effects of a Paleolithic diet on cardiovascular risk factors in type 2 diabetes: a randomized cross-over pilot study. Cardiovasc Diabetol 2009, 8:35.

18. Ryberg M, Sandberg S, Mellberg C, Stegle O, Lindahl B, Larsson C, Hauksson J, Olsson T: A Palaeolithic-type diet causes strong tissue-specific effects on ectopic fat deposition in obese postmenopausal women. J Int Med 2013, 274(1):67-76.

19. Mellberg C, Sandberg S, Ryberg M, Eriksson M, Brage S, Olsson T, Lindahl B: Long-term effects of a Palaeolithic-type diet in obese postmenopausal women: a 2-year randomized trial. Eur J Clin Nutr 2014, 68:350-357.

20. Expert Panel on Detection, Evaluation, and Treatment of High Blood Cholesterol in Adults (Adult Treatment Panel III): Executive Summary of the Third Report of the National Cholesterol Education Program (NCEP). JAMA 2001, 285(19):2486-2497.

21. Cordain L, Miller JB, Eaton SB, Mann N, Holt SH, Speth JD: Plant-animal subsistence ratios and macronutrient energy estimations in worldwide hunter-gatherer diets. Am J Clin Nutr 2000, 71(3):682-692.

22. Kuipers RS, Luxwolda MF, Dijck-Brouwer DA, Eaton SB, Crawford MA, Cordain L, Muskiet FA: Estimated macronutrient and fatty acid intakes from an East African Paleolithic diet. Br J Nutr 2010, 104(11):1666-1687.

23. Dutch Health Council: Dietary reference intakes: energy, proteins, fats, and digestible carbohydrates. The Hague; 2001. Publication nr 2001/19.

24. Dutch Health Council: Guidelines for a healthy diet. The Hague; 2006. Publication nr 2006/21.

25. Dutch Health Council: Guideline for dietary fiber intake. The Hague; 2006. Publication nr 2006/03.

26. Dutch Health Council: Dietary reference intakes: calcium, vitamin D, thiamin, riboflavin, niacin, pantothenic acid, and biotin. The Hague; 2000. Publication nr 2000/12.

27. Dutch Health Council: Towards maintaining an optimum iodine intake. The Hague; 2008. Publication nr 2008/14.

28. Dutch Health Council: Towards an adequate intake of vitamin A. The Hague; 2008. Publication nr 2008/26

29. Dutch Health Council: Dietary Reference Intakes: vitamin B6, folic acid and vitamin B12. The Hague; 2003. Publication nr 2003/04 
30. Dutch Health Council: Evaluation of the dietary reference values for vitamin D. The Hague; 2012. Publication nr 2012/15.

31. Dutch Nutrients File (NEVO). http://nevo-online.rivm.nl.

32. American Diabetes Association: Diagnosis and Classification of Diabetes Mellitus. Diabetes Care 2013, 36(Suppl 1):S67-S74.

33. Adam EK, Kumari M: Assessing salivary cortisol in large-scale epidemiological research. Psychoneuroendocrinology 2009, 34:1423-1436.

34. Raison CL, Borisov AS, Woolwine BJ, Massung B, Vogt G, Miller AH: Interferon-alpha effects on diurnal hypothalamic-pituitary-adrenal axis activity: relationship with proinflammatory cytokines and behavior. Mol Psychiatry 2010, 15(5):535-547.

35. Rosmond R, Bjorntorp P: The hypothalamic-pituitary-adrenal axis activity as a predictor of cardiovascular disease, type 2 diabetes and stroke. J Intern Med 2000, 247:188-197.

36. Matthews K, Schwartz J, Cohen S, Seeman T: Diurnal cortisol decline is related to coronary calcification: CARDIA study. Psychosom Med 2006, 68:65-661.

37. Ajala O, English P, Pinkney J: Systematic review and meta-analysis of different dietary approaches to the management of type 2 diabetes. Am J Clin Nutr 2013, 97(3):505-516.

38. Jönsson T, Granfeldt $Y$, Erlanson-Albertsson $C$, Ahrén B, Lindeberg $S$ : A paleolithic diet is more satiating per calorie than a mediterranean-like diet in individuals with ischemic heart disease. Nutr Metab 2010, 7:85.

39. Jönsson T, Granfeldt Y, Lindeberg S, Hallberg AC: Subjective satiety and other experiences of a Paleolithic diet compared to a diabetes diet in patients with type 2 diabetes. Nutr J 2013, 29(12):105.

40. Weigle DS, Breen PA, Matthys CC, Callahan HS, Meeuws KE, Burden VR, Purnell JQ: A high-protein diet induces sustained reductions in appetite, ad libitum caloric intake, and body weight despite compensatory changes in diurnal plasma leptin and ghrelin concentrations. Am J Clin Nutr 2005, 82:41-48.

41. Halton TL, Hu FB: The effects of high protein diets on thermogenesis, satiety and weight loss: a critical review. J Am Coll Nutr 2004, 23(5):373-385.

42. Spreadbury I: Comparison with ancestral diets suggests dense acellular carbohydrates promote an inflammatory microbiota, and may be the primary dietary cause of leptin resistance and obesity. Diabetes Metab Syndr Obes 2012, 5:175-189.

doi:10.1186/1476-511X-13-160

Cite this article as: Boers et al:: Favourable effects of consuming a Palaeolithic-type diet on characteristics of the metabolic syndrome: a randomized controlled pilot-study. Lipids in Health and Disease 2014 13:160.

\section{Submit your next manuscript to BioMed Central and take full advantage of:}

- Convenient online submission

- Thorough peer review

- No space constraints or color figure charges

- Immediate publication on acceptance

- Inclusion in PubMed, CAS, Scopus and Google Scholar

- Research which is freely available for redistribution 